\title{
Worker Honeybee Sterility: A Proteomic Analysis of Suppressed Ovary Activation
}

\author{
Dries Cardoen, ${ }^{*}, \dagger$ Ulrich R. Ernst, ${ }^{\dagger, \ddagger}$ Bart Boerjan, ${ }^{\dagger}$ Annelies Bogaerts, ${ }^{\dagger}$ Ellen Formesyn, ${ }^{\S}$ \\ Dirk C. de Graaf, ${ }^{\S}$ Tom Wenseleers, ${ }^{\ddagger}$ Liliane Schoofs, ${ }^{\dagger}$ and Peter Verleyen ${ }^{\dagger}$ \\ ${ }^{\dagger}$ Research group of Functional Genomics and Proteomics, KU Leuven, Belgium \\ ${ }^{\ddagger}$ Laboratory of Entomology, KU Leuven, Belgium \\ ${ }^{\S}$ Laboratory of Zoophysiology, Ghent University, Belgium
}

\section{Supporting Information}

\begin{abstract}
Eusocial behavior is extensively studied in the honeybee, Apis mellifera, as it displays an extreme form of altruism. Honeybee workers are generally obligatory sterile in a bee colony headed by a queen, but the inhibition of ovary activation is lifted upon the absence of queen and larvae. Worker bees are then able to develop mature, viable eggs. The detailed repressive physiological mechanisms that are responsible for this remarkable phenomenon are as of yet largely unknown. Physiological studies today mainly focus on the transcriptome, while the proteome stays rather unexplored. Here, we present a quantitative 2-dimensional differential gel electrophoresis comparison between activated and inactivated worker ovaries and brains of reproductive and sterile worker

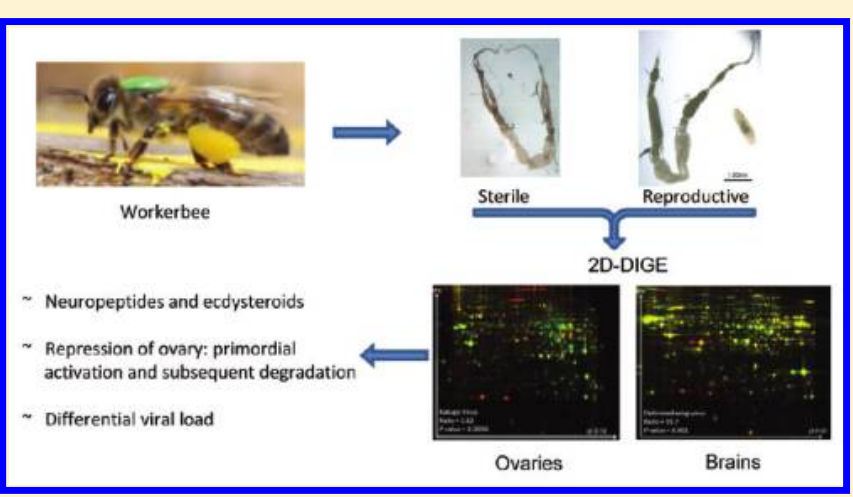
bees, including a spot map of ovaries, containing 197 identified spots. Our findings suggest that suppression of ovary activation might involve a constant interplay between primordial oogenesis and subsequent degradation, which is probably mediated through steroid and neuropeptide hormone signaling. Additionally, the observation of higher viral protein loads in both the brains and ovaries of sterile workers is particularly noteworthy. This data set will be of great value for future research unraveling the physiological mechanisms underlying the altruistic sterility in honeybee workers.
\end{abstract}

KEYWORDS: Apis mellifera, ovary and brain proteome, worker sterility, deformed wing virus

\section{INTRODUCTION}

Honeybees display an extreme form of eusociality where one queen produces virtually all the offspring and tens of thousands female workers refrain from reproducing. The altruistic sterility of the female worker bees has fascinated scientists for decades. ${ }^{1,2}$ The main functional and morphological difference between the two different female casts in a honeybee society (queen vs workers) is the extent of ovarian development. In queens, both ovaries consist of 150-180 ovarioles, which are enlarged and produce up to 2000 eggs per day. ${ }^{3}$ The development of ovarioles in workers, on the other hand, is repressed during the late larval stages by means of apoptosis, due to the reduced amount of royal jelly in the diet. ${ }^{4}$ This results in ovaries with only 3-26 ovarioles. ${ }^{3}$ These ovaries stay inactivated throughout the adult life of a worker bee. Only when a colony becomes hopelessly queenless, for example, when a queen happens to die and the subsequent breeding of a replacement queen fails, up to $30 \%$ of the worker bees start to develop viable eggs. ${ }^{5}$ Since worker bees are unable to copulate, all such worker-laid eggs remain unfertilized and, due to the haplo-diploid sex determination, develop into males. The regulatory network repressing the ovary activation in honeybee workers in the presence of the queen remains largely enigmatic.

One theory regarding the regulation of worker ovary development that is receiving increasing empirical support is the Reproductive Ground Plan Hypothesis (RGPH). ${ }^{6-10}$ This hypothesis states that the honeybee's reproductive division of labor is controlled by the same gene set that regulated the multiple switching between the reproducing/nonforaging stage (queen-like) and the nonreproducing/foraging stage (workerlike) in the hypothetically solitary ancestors. Amdam et al. expanded this model by suggesting that the same set of genes that determines whether a larva develops into a queen or a worker also regulates the division of labor within the foraging population. ${ }^{8}$ This idea was supported by the correlation between worker ovary development and pollen foraging in a line of bees selected for high-pollen hoarding. Today, this theory is discussed among evolutionary biologists. ${ }^{11-13}$ Worker reproductive capacity in the RGPH has been defined according to the number of ovarioles, and a correlation between the

Received: December 13, 2011

Published: April 6, 2012 
number of ovarioles and egg development has been reported for Africanized honeybees. ${ }^{14}$ However, we focus here on the presence or absence of developed oocytes inside the ovaries, independent of the number of ovarioles. Here we aim at identifying more proximate factors involved in the regulation of worker ovary activation in the honeybee.

Though the honeybee genome sequence was released in $2006^{15}$ and a number of microarray screenings have since been conducted to investigate, for example, task allocation and fertility, ${ }^{16-22}$ studies on this topic at the level of the proteome are still scarce. ${ }^{23,24}$ Using a 2-dimensional differential gel electrophoresis (2D-DIGE) approach, we compare proteome profiles of activated versus inactivated ovaries dissected from age-matched worker bees from hopelessly queenless colonies. In addition, 2D-DIGE proteome maps of brains from reproductive and sterile workers are compared. We hypothesized a priori that a small subset of yolk proteins would be upregulated in activated ovaries with mature eggs and that several structural proteins would be over-represented in inactivated ovaries, considering that this rudimentary organ consists mainly of membranes. We feature a spot map of ovarian protein extracts displaying 197 identified spots, 119 of which are differential (61 up-regulated in activated ovaries, 58 upregulated in rudimentary ovaries). Furthermore, comparing ovaries and brains from sterile and reproductive workers confirmed earlier findings that sterile worker bees have higher viral protein loads of the Deformed wing virus (DWV). ${ }^{25}$ Remarkably, results from additional experiments on the RNAlevel by means of quantitative real time PCR (qRT-PCR) do not correspond with the proteomics data.

\section{MATERIAL AND METHODS}

\section{Sample Collection}

Three honeybee colonies (ca. 10,000 bees), each headed by a singly mated queen (obtained from the DLR Fachzentrum für Bienen and Imkerei, Mayen, Germany), were kept at the apiary of the Laboratory of Zoophysiology, Ghent, following standard beekeeping methods. To initiate worker ovary activation, queens were removed and subsequent queen-rearing cells were annihilated. From the day of queen removal on, emerging bees were paint marked (Posca paint markers) and introduced in the colonies on a daily basis. For this purpose, a frame with sealed brood was placed in an incubator (Memmert Precision Incubator Model INE 700, $34{ }^{\circ} \mathrm{C}$, high relative humidity), allowing us to collect the emerging bees every $24 \mathrm{~h}$ and to return them paint marked on the thorax (changing color every $24 \mathrm{~h}$ ) to their original colony. ${ }^{26}$ At 18 days of age, all marked bees were recaptured in the early morning and immediately anesthetized on ice.

\section{Sample Preparation and 2D-DIGE}

Ovary Samples. Ovary samples were dissected in insect saline buffer ( $150 \mathrm{mM} \mathrm{NaCl}, 10 \mathrm{mM} \mathrm{KCl}, 4 \mathrm{mM} \mathrm{CaCl}, 2 \mathrm{mM}$ $\mathrm{MgCl}_{2}, 10 \mathrm{mM}$ 2-[4-(2-hydroxyethyl)piperazin-1-yl]ethanesulfonic acid) and categorized based on ovary activation. An ovary was scored as "fully activated" if at least one oocyte was larger than $1.1 \mathrm{~mm}$ and "completely inactivated" if the length of the largest oocyte was shorter than $0.3 \mathrm{~mm}$ (Figure 1). Bees with intermediate ovary activation were not included in this analysis. The dissected organs were immediately snap frozen in liquid nitrogen and stored at $-80{ }^{\circ} \mathrm{C}$ until further analysis. Frozen bee ovaries were suspended in a lysis solution (7 M urea, $2 \mathrm{M}$ thiourea, 4\% CHAPS, $40 \mathrm{mM}$ Tris, 1\% DTT

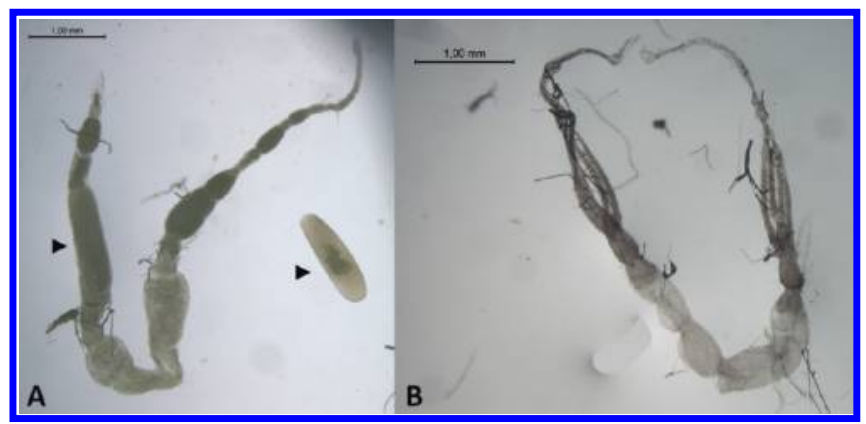

Figure 1. Dissected worker ovaries. (A) Ovary, scored as completely activated (largest oocyte $>1.1 \mathrm{~mm}$, see arrowheads). (B) Ovary, scored as completely inactivated (largest oocyte $<0.3 \mathrm{~mm}$ ).

and Complete protease inhibitor, Roche). Each sample of inactivated ovaries consisted of at least 40 rudimentary ovaries in $80 \mu \mathrm{L}$ lysis solution. Each sample of activated ovaries consisted of 10 fully activated ovaries in $100 \mu \mathrm{L}$ of lysis solution. In total, 4 biological replicates, each comparing a sample of activated ovaries with a sample of rudimentary ovaries, were obtained for ovary 2D-DIGE comparison, originating from two colonies. In total, this experiment includes 40 and 160 activated and rudimentary ovaries respectively.

Brain Samples. Brain samples were dissected in insect saline buffer and contain the entire central nervous system from the head, including the optic lobes, ocelli and calyx. Each brain sample consisted of five brains, dissected from bees with either rudimentary or activated ovaries, that were suspended in 150 $\mu \mathrm{L}$ of the lysis solution described earlier. The experiment included 12 replicates from three colonies (six replicates from colony one and three replicates from colony two and three). In total, this experiment includes 60 brains from reproductive bees and 60 brains of sterile bees.

Labeling. During all procedures, the samples were kept on ice or $4{ }^{\circ} \mathrm{C}$ as much as possible. The extracts were sonicated for 5 s (MSE Sanyo Soniprep 150). Then, the samples were centrifuged for $10 \mathrm{~min}$ at $15800 \mathrm{rcf}$ and $4{ }^{\circ} \mathrm{C}$. Supernatants were desalted by means of the PlusOne Mini Dialysis Kit (GE Healthcare), protein concentration was determined using the Bradford method ${ }^{27}$ and the $\mathrm{pH}$ was measured ( $\mathrm{pH} 315 \mathrm{i}$, WTW and Biotrode $\mathrm{pH} 0-14$, Hamilton). Fifty micrograms of protein for each ovary sample and $75 \mu \mathrm{g}$ for each brain sample were labeled with 250 pmol CyDye (GE Healthcare), following a balanced dye-swap protocol. The CyDye, dissolved in anhydrous dimethylformamide (Sigma-Aldrich), was added to the sample and incubated on ice in the dark for $45 \mathrm{~min}$. The reaction was terminated by adding $1 \mu \mathrm{L}$ aqueous lysine solution $(10 \mathrm{mM})$. Gel preparations and gel electrophoresis were performed as described. ${ }^{28}$ After electrophoresis, the gels were scanned using an Ettan DIGE Imager (GE Healthcare) according to manufacturer's instructions. The images of the analytical gels were imported and processed in the Decyder 7.0 software (GE Healthcare). Subsequently, raw spot volumes for the $\mathrm{Cy} 3$ and $\mathrm{Cy} 5$ channels were exported and analyzed using the Bioconductor package limma. ${ }^{29}$ To perform the statistical analysis on the spots that consistently appear in all gels, we filtered the spot list for spots that were detected in at least $75 \%$ of the gels. The Cy3 and Cy5 channels were normalized within and between gels using loess and quantile normalization respectively. Finally, differential expression was measured according to the $\log _{2}$ spot volume ratios and its statistical significance was assessed using empirical Bayes moderated $t$ - 
tests carried out in limma. ${ }^{25,30-33}$ In this analysis, colony was included as a random blocking variable and $p$-values were corrected using Benjamini-Hochberg procedures ${ }^{34}$ to control the false discovery rate (FDR). All spots with an FDR-adjusted $p$-value smaller than 0.05 were considered as differentially expressed and were used for further analysis. All $p$-values mentioned are FDR-adjusted. A full description of the 2DDIGE protocol used here is available at the Minimum Information About a Proteomics Experiment Gel Database (MIAPEGelDB: Bee_Ovary_prot; http://miapegeldb.expasy. org/experiment/91/gel/208/as_html/).

\section{Protein Identification}

Preparative gels were run with protein extracts from activated and inactivated ovaries as well as brain extracts. Plus One BindSilane and two reference markers (GE Healthcare) were added to the gels, according to manufacturer's guidelines. Each preparative gel contained $400-600 \mu \mathrm{g}$ of protein. After $2 \mathrm{D}$ electrophoresis, the gels were stained with Deep Purple Total Protein Stain (GE Healthcare) and imaging was performed using the Ettan DIGE Imager. The images were imported in the Decyder 7.0 software and matched against the analytical gels. Pick lists contained the differentially expressed spots (for both the ovary and brain experiment) and consistently appearing spots (only for the ovary experiment). The spots were picked with the Ettan Spot Picker (GE Healthcare) and stored in Milli$\mathrm{Q}$ water at $-20{ }^{\circ} \mathrm{C}$ until tryptic digestion. Gel pieces were dehydrated three times with $50 \mu \mathrm{L}$ of acetonitrile, after which they were rehydrated with $50 \mu \mathrm{L}$ of $100 \mathrm{mM}$ of ammonium bicarbonate for $10 \mathrm{~min}$. Gel pieces were subsequently dehydrated in $50 \mu \mathrm{L}$ of acetonitrile for $10 \mathrm{~min}$. The last two steps were repeated twice. The enzymatic digestion was initiated by adding $25 \mu \mathrm{L}$ of digestion buffer $(50 \mathrm{mM}$ ammonium bicarbonate and $5 \mathrm{mM} \mathrm{CaCl}$ ) containing $6 \mathrm{ng} /$ $\mu \mathrm{L}$ trypsin (Promega). After $45 \mathrm{~min}$ incubation on ice, the enzymatic digestion was continued overnight at $37{ }^{\circ} \mathrm{C}$. The resulting peptides were extracted once with $80 \mu \mathrm{L}$ of $50 \mathrm{mM}$ ammonium bicarbonate $(30 \mathrm{~min}$.) and two times with $80 \mu \mathrm{L}$ of $50 \%$ acetonitrile and $5 \%$ formic acid (each time $30 \mathrm{~min}$ ). Supernatants of the three extractions were pooled together and dried in a vacuum centrifuge.

The dry extracts were desalted using Ziptip $\mathrm{C}_{18}$ (Millipore) and spotted on a MALDI Target ground steel plate. The samples were mixed in a 2:1 (v:v) ratio with $\alpha$-cyano-4hydroxycinnamic acid matrix (saturated solution in 50\% acetonitrile, $0.5 \%$ formic acid). The spots in the ovary experiment were measured with a MALDI-TOF device (Reflex IV, Bruker). Settings of the mass spectrometer were adopted from Vierstraete et al. ${ }^{35}$ with minor adjustments. External calibration was done with Peptide calibration standard (1000$4000 \mathrm{Da}$, Bruker Daltonics). Laser power was optimized for best resolution and signal-to-noise ratio. Spots with no or an inadequate identification were reanalyzed using an Ultraflex II mass spectrometer (Bruker). Postacquisition processing was carried out in Flex Analysis (Bruker Daltonics) and consisted of baseline subtraction (TopHat) and smoothing (Savitzky Golay). The peak detection in Flex Analysis was carried out using the SNAP algorithm (S/N ratio, 3; max. number of spots, 150; quality factor threshold, 30). The proteins were identified through peptide mass fingerprinting (PMF) using Mascot, ${ }^{36}$ against the protein database of the Apis mellifera official gene set prerelease 2 (containing 11062 sequences), (http://genomes. arc.georgetown.edu/Amel_pre_release2_OGS_pep.fa). Carba- midomethylation was set as fixed modification, oxidation (M) as variable modification and up to one missed cleavage was allowed. The mass tolerance was set at $0.2 \mathrm{Da}$ as a default value. In addition, every spectrum was also searched against the publicly available NCBInr database as a control for potential contamination with e.g. human keratin. Virus proteins from the brains were identified by means of MALDI-TOF/TOF mass spectrometry (UltraFlex II, Bruker Daltonics) and Mascot MS/ MS Ion searches against the Apis mellifera official gene set release 1 (containing 9939 sequences), available at Beebase, and NCBInr as a control. Both the peptide mass tolerance and fragment mass tolerance were set at $0.2 \mathrm{Da}$; carbamidomthylation (C) was a fixed modification and oxidation (M) was set as variable modification.

\section{Functional Gene Ontology Enrichment Analysis}

In the comparison of the proteome of fully activated and inactivated honeybee worker ovaries, a sufficient number of differentially expressed proteins (119) was obtained to be able to carry out a functional gene ontology (GO) enrichment analysis. We analyzed the differentially expressed ovarian gene set in silico. Using the Bioconductor TopGO package, in particular the modified hypergeometric test-based method "elim", 37 we determined which biological processes are significantly enriched in the sets of differential proteins from activated and rudimentary ovaries. In case multiple spots contain the same protein, only the spot with the largest log ratio was used in the analysis. Gene ontology annotation information was collected by making use of various databases and resources, including Blast2Go, Pfam, Flybase, DAVID and Uniprot. ${ }^{38}$ This resulted in the successful annotation of 154 out of 162 identified proteins with Biological Process Gene Ontology (GO) terms. In all cases, enrichment was tested relative to the remainder of the proteins identified in this study. Enrichment relative to the rest of the genome was not tested given the inherent biases and limitations of the 2-DE technique, for example, the fact that highly hydrophobic proteins, extremely heavy proteins and small peptides are not detected. ${ }^{39}$

\section{RNA Analysis of Deformed Wing Virus}

Additional samples were collected from two colonies, each headed by a naturally inseminated, multiple-mated queen. Queen and open brood from both colonies were removed at the same time. Following standard procedures, broodframes with emerging brood from the experimental colonies were kept in an incubator at $34{ }^{\circ} \mathrm{C}$. Bees were paint marked, according to their age, within $24 \mathrm{~h}$ after emergence and introduced into their colony of origin. Marked bees of 18-days old were recaptured and the ovary activation was scored. As RNA extraction from rudimentary ovaries did not deliver RNA of sufficient quality, even when employing an RNA extraction kit suited for small tissues (RNeasy Micro, Qiagen), we opted to sample complete abdomens and dissected brains. RNA was extracted by means of the RNeasy Lipid Tissue kit (Qiagen) following manufacturers' guidelines. RNA concentration and quality was determined using Nanodrop ND-1000 (Nanodrop Technologies). Seven replicates of two colonies, resulting in 14 biological replicates were included both for entire abdomen samples and for dissected brain samples. Both DWV and the reference gene (GB10903) were detected by a one-step qRT-PCR protocol with Taqman probes (DWV-Fw: GTTAATCAGCGCTTAGTGGAGGAA; DWV-Rev: CCGCACCTACGCGATGTAA; DWV-probe: AGGAGCGTACACTATGGT; GB10903Fw: CAGTAAATTAAAGAGAAACTGGCGTAAA; GB10903- 


\begin{tabular}{|c|c|c|c|c|c|c|c|c|}
\hline & Spot & BeeBase & Ratio & Adjusted $\mathrm{p}$. & & & & \\
\hline Annotation & $\mathrm{Nr}$ & $\mathrm{Nr}$ & (infertile/fertile) & value & 1 & 2 & 3 & 4 \\
\hline similar to Lipid storage droplet-2 CG9057-PA & 1957 & GB14434 & $-12,82$ & 0,0012 & & & & \\
\hline vitellogenin & 293 & GB13999 & $-11,35$ & 0,0012 & & & & \\
\hline similar to $\mathrm{Hsp} 70 / \mathrm{Hsp} 90$ organizing protein homolog & 965 & GB19425 & $-7,44$ & 0,0012 & & & & \\
\hline vitellogenin & 298 & GB13999 & $-7,05$ & 0,0019 & & & & \\
\hline FK506-binding protein FKBP59 & 1406 & GB13770 & $-6,14$ & 0,0012 & & & & \\
\hline vitellogenin & 1697 & GB13999 & $-5,64$ & 0,0038 & & & & \\
\hline arginine kinase & 1605 & GB10973 & $-5,15$ & 0,0043 & & & & \\
\hline similar to squid CG16901-PC, isoform C & 1808 & GB15796 & $-5,03$ & 0,0012 & & & & \\
\hline similar to squid CG16901-PC, isoform C & 1780 & GB15796 & $-4,98$ & 0,0011 & & & & \\
\hline superoxide dismutase 1 & 2635 & GB10133 & $-4,76$ & 0,0025 & & & & \\
\hline similar to $60 \mathrm{kDa}$ heat shock protein & 1008 & GB18969 & $-4,67$ & 0,0025 & & & & \\
\hline heat shock protein 90 & 2736 & GB14758 & $-4,63$ & 0,0055 & & & & \\
\hline calponin-like protein Chd64 & 2507 & GB12375 & $-4,47$ & 0,0014 & & & & \\
\hline glutathione peroxidase-like 1 & 2542 & GB14138 & $-4,33$ & 0,0012 & & & & \\
\hline arginine kinase & 1649 & GB10973 & $-4,01$ & 0,0085 & & & & \\
\hline similar to Cofilin/actin-depolymerizing factor & 2614 & GB18917 & $-3,77$ & 0,0039 & & & & \\
\hline thioredoxin peroxidase 1 & 2453 & GB19380 & $-3,71$ & 0,0017 & & & & \\
\hline similar to Cofilin/actin-depolymerizing factor & 2644 & GB18917 & $-3,25$ & 0,0078 & & & & \\
\hline ATP synthase, $\mathrm{H}+$ transporting & 2734 & GB14791 & $-3,05$ & 0,0034 & & & & \\
\hline similar to CG6459-PA & 2730 & GB10107 & $-3,03$ & 0,0037 & & & & \\
\hline vacuolar $\mathrm{H}[+]-$ ATPase $26 \mathrm{kD}$ E subunit & 2080 & GB12913 & $-2,96$ & 0,0032 & & & & \\
\hline similar to Aldehyde dehydrogenase & 1112 & GB12741 & $-2,87$ & 0,0025 & & & & \\
\hline 14-3-3 protein zeta & 2211 & GB12951 & $-2,80$ & 0,0015 & & & & \\
\hline similar to Vacuolar H+-ATPase $55 \mathrm{kD}$ B subunit & 1048 & GB19171 & $-2,59$ & 0,0046 & & & & \\
\hline phosphoglycerate mutase & 2160 & GB15052 & $-2,52$ & 0,0037 & & & & \\
\hline ATP-dependent RNA helicase me $31 \mathrm{~b}$ ortholog & 1321 & GB16998 & $-2,35$ & 0,0254 & & & & \\
\hline heat shock protein $70 \mathrm{Cb}$ ortholog & 406 & GB10836 & $-2,33$ & 0,0031 & & & & \\
\hline heat shock protein cognate 4 & 779 & GB14852 & $-2,29$ & 0,0162 & & & & \\
\hline similar to Glycoprotein 93 CG5520-PA & 480 & GB12703 & $-2,14$ & 0,0038 & & & & \\
\hline ERp60 protein & 1042 & GB10238 & $-2,13$ & 0,0174 & & & & \\
\hline similar to CG32068-PA & 2412 & GB19130 & $-2,10$ & 0,0041 & & & & \\
\hline heat shock protein cognate 5 & 764 & GB19860 & $-2,09$ & 0,0048 & & & & \\
\hline $26 \mathrm{~S}$ proteasome non-ATPase regulatory subunit 13 & 1572 & GB16614 & $-2,05$ & 0,0035 & & & & \\
\hline similar to CG7033-PA, isoform A & 1018 & GB10699 & $-2,02$ & 0,0143 & & & & \\
\hline heat shock protein cognate 5 & 774 & GB19860 & $-2,02$ & 0,0058 & & & & \\
\hline Tat-binding protein-1 & 1333 & GB14678 & $-2,01$ & 0,0116 & & & & \\
\hline heat shock $70 \mathrm{kDa}$ protein cognate 3 & 743 & GB15016 & $-2,00$ & 0,0452 & & & & \\
\hline T-complex protein 1 subunit eta & 1033 & GB10561 & $-1,98$ & 0,0044 & & & & \\
\hline heat shock $70 \mathrm{kDa}$ protein cognate 3 & 742 & GB15016 & $-1,97$ & 0,0043 & & & & \\
\hline ERp60 protein & 1029 & GB10238 & $-1,88$ & 0,0097 & & & & \\
\hline similar to CG14207-PB, isoform B & 2297 & GB15718 & $-1,88$ & 0,0246 & & & & \\
\hline heat shock protein $70 \mathrm{Cb}$ ortholog & 395 & GB10836 & $-1,85$ & 0,0085 & & & & \\
\hline t-complex chaperonin 5 & 1031 & GB10587 & $-1,83$ & 0,0065 & & & & \\
\hline similar to Tropomyosin 1 CG4898-PD, isoform D & 2064 & GB17608 & $-1,83$ & 0,0221 & & & & \\
\hline similar to Proteasome p44.5 subunit CG10149-PB & 1431 & GB18440 & $-1,81$ & 0,0055 & & & & \\
\hline soluble NSF attachment protein & 1982 & GB15709 & $-1,77$ & 0,0089 & & & & \\
\hline similar to Vacuolar ATP synthase catalytic subunit A & 772 & GB10989 & $-1,76$ & 0,0238 & & & & \\
\hline puromycin sensitive aminopeptidase & 540 & GB13772 & $-1,73$ & 0,0459 & & & & \\
\hline 6-phosphogluconate dehydrogenase, decarboxylating & 1304 & GB12949 & $-1,73$ & 0,0322 & & & & \\
\hline similar to Dipeptidyl aminopeptidase III CG7415-PC & 710 & GB19373 & $-1,71$ & 0,0167 & & & & \\
\hline ALG-2 interacting protein $X$ & 543 & GB11744 & $-1,67$ & 0,0083 & & & & \\
\hline GDP dissociation inhibitor & 1222 & GB13730 & $-1,62$ & 0,0242 & & & & \\
\hline heat shock protein cognate 4 & 758 & GB14852 & $-1,60$ & 0,0393 & & & & \\
\hline Rpn5 protein & 1282 & GB11260 & $-1,57$ & 0,0393 & & & & \\
\hline ATP synthase subunit beta, mitochondrial & 1263 & GB13596 & $-1,56$ & 0,0486 & & & & \\
\hline similar to CG3011-PA & 1285 & GB14485 & $-1,55$ & 0,0153 & & & & \\
\hline similar to CG8036-PB, isoform B & 904 & GB15619 & $-1,54$ & 0,0162 & & & & \\
\hline thioredoxin peroxidase 3 & 2417 & GB10972 & $-1,53$ & 0,0179 & & & & \\
\hline similar to Sterol carrier protein $\mathrm{X}$-related thiolase & 1090 & GB10657 & $-1,49$ & 0,0224 & & & & \\
\hline
\end{tabular}

Figure 2. continued 


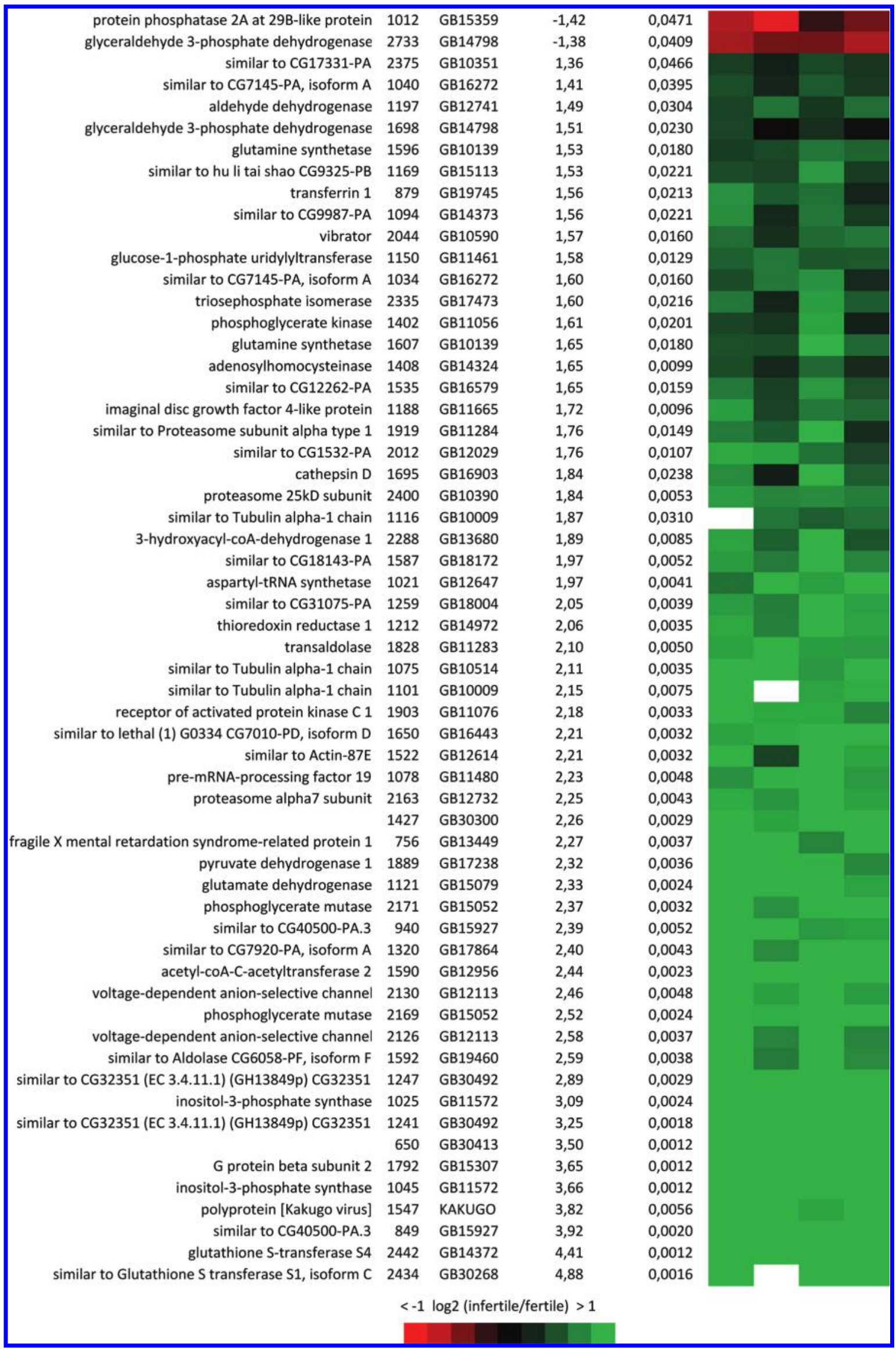

Figure 2. continued 
Figure 2. continued

Figure 2. Overview of all differentially expressed proteins, displaying the annotation, spot number (according to Figure S1 and Table S1, Supporting Information) together with the BeeBase number (GB identifier) and the $\log _{2}$ ratio (infertile/fertile) and matching adjusted $p$-value. For each protein, the $\log _{2}$ ratio for each gel is presented in a heat map.

Table 1. Summary of the GO-Enrichment Analysis using TopGO, in the Differential Proteomics Experiment of Ovaries ${ }^{a}$

\begin{tabular}{|c|c|c|c|c|c|c|c|c|c|}
\hline \multicolumn{5}{|c|}{ nonreproductive workers } & \multicolumn{5}{|c|}{ reproductive workers } \\
\hline GO biological process term & GO nr. & NS & FE & $p$-value & GO biological process term & GO nr. & NS & FE & $p$-value \\
\hline \multicolumn{5}{|c|}{ Metabolism } & \multicolumn{5}{|c|}{ Metabolism } \\
\hline Carbohydrate catabolic process & 0016052 & 9 & 1.91 & 0.0132 & $\begin{array}{l}\text { ATP synthesis coupled proton } \\
\text { transport }\end{array}$ & 0015986 & 5 & 2.84 & 0.004 \\
\hline Organic acid metabolic process & 0006082 & 11 & 1.72 & 0.0169 & & & & & \\
\hline Glycolysis & 0006096 & 6 & 2.23 & 0.0172 & & & & & \\
\hline Cellular lipid metabolic process & 0044255 & 6 & 2.23 & 0.0172 & & & & & \\
\hline Alcohol catabolic process & 00416164 & 8 & 1.83 & 0.0289 & & & & & \\
\hline Pyruvate metabolic process & 0006090 & 4 & 2.38 & 0.0433 & & & & & \\
\hline Fatty acid metabolic process & 0006631 & 4 & 2.38 & 0.0433 & & & & & \\
\hline \multicolumn{5}{|c|}{ Egg Development } & \multicolumn{5}{|c|}{ Stress and Protein Folding } \\
\hline $\begin{array}{l}\text { Neg. regulation of cell. component } \\
\text { organization }\end{array}$ & 0051129 & 5 & 2.98 & 0.0036 & Protein folding & 0006457 & 13 & 2.17 & 0.0003 \\
\hline Neg. regulation of organelle organization & 0010639 & 4 & 2.99 & 0.0116 & Protein complex assembly & 0006461 & 5 & 2.84 & 0.0046 \\
\hline Neg. regulation of cell cycle & 0045786 & 3 & 2.97 & 0.0362 & Response to stress & 0006950 & 13 & 3.30 & 0.0364 \\
\hline Neg. regulation of nuclear division & 0051784 & 3 & 2.97 & 0.0362 & Response to heat & 0009408 & 3 & 2.86 & 0.0416 \\
\hline \multicolumn{5}{|c|}{ Other } & \multicolumn{5}{|c|}{ Egg Development } \\
\hline \multirow[t]{4}{*}{ Locomotory behavior } & 0007626 & 3 & 2.97 & 0.036 & Vesicle mediated transport & 0016192 & 6 & 2.44 & 0.0076 \\
\hline & & & & & $\begin{array}{l}\text { Cell. macromolecular complex } \\
\text { assembly }\end{array}$ & 0034622 & 4 & 2.84 & 0.014 \\
\hline & & & & & \multicolumn{5}{|c|}{ Pathways } \\
\hline & & & & & Intracellular signaling cascade & 0007242 & 3 & 2.86 & 0.0416 \\
\hline
\end{tabular}

${ }^{a_{T}}$ The GO biological process terms, which are enriched in the differentially expressed protein set of either reproductive or sterile worker bees are depicted, together with their GO-numbers (NS: the number of differentially expressed proteins in the set, with the annotated GO-term; FE: fold enrichment). Full results are available in Tables S2 and S3 (Supporting Information).

Rev: GCATCAAATATTGTCCCTTAAAACG; GB10903probe: AAAGGTATTGATAACAGAGTTC). Reaction volumes consisted of $5 \mu \mathrm{L}$ of TaqMan Fast Virus 1-Step Master Mix (Applied Biosystems), $12 \mu \mathrm{L}$ Milli-Q water and $1 \mu \mathrm{L}$ of the Custom TaqMan Gene Expression Assays (20× concentration, Applied Biosystems) containing previously mentioned primers and probes for each target specifically. The reaction volume was completed with $2 \mu \mathrm{L}$ of total RNA, resulting in a total volume of $20 \mu \mathrm{L}$. Real time PCR was run by a StepOne Plus (Applied Biosystems) starting the reverse transcriptase step at $50{ }^{\circ} \mathrm{C}$ for $5 \mathrm{~min}$, followed by $20 \mathrm{~s}$ at $95{ }^{\circ} \mathrm{C}$ to degrade the reverse transcriptase. Immediately after, the real time cycling started for $15 \mathrm{~s}$ at $95^{\circ} \mathrm{C}$ and $1 \mathrm{~min}$ at $60^{\circ} \mathrm{C}$ and was repeated 50 times. Ct values were obtained through the StepOne Real-Time System Software (Applied Biosystems). Relative transcript abundances were assessed by means of the delta delta $\mathrm{Ct}$ method. ${ }^{40}$

\section{RESULTS}

\section{Ovary Proteome}

The quantitative comparison between fully activated and rudimentary honeybee worker ovaries resulted in an initial set of 613 differentially expressed features out of 1666 detected spots (277 higher in activated ovaries and 336 higher in rudimentary ovaries). In total, 119 differential spots could be identified, of which 58 were up-regulated in ovaries from sterile workers and 61 in activated ovaries. A further 78 additional random spots were identified to complete the spot map, resulting in a total of 223 identified proteins from 197 spots
(Figures 2 and S1, Table S1, Supporting Information, WORLD 2-Dimensional Differential Gel Electrophoresis Constellation at Expert Protein Analysis System, Expasy WORLD-2DPAGE experiment 29; http://world-2dpage.expasy.org/repository/ database $=0029)$. Gene Ontology (GO) enrichment analysis results are summarized in Table 1; complete data are available in Tables S2 and S3, Supporting Information. Surprisingly, one of the spots with the highest up-regulation in rudimentary ovaries (ratio $=3.8 ; p=0.006$ ) is the polyprotein of the Kakugo-virus (KV).

\section{Brain Proteome}

Whereas 1514 spots are detected in $75 \%$ of the gels, only two spots are significantly differential. The first is up-regulated by 4fold in sterile workers $\left(p_{\text {adj }}=0.004\right)$, but could not be identified. The second spot (2517), identified as the polyprotein from the DWV, is enriched nearly 9-fold in the sterile workers $\left(p_{\text {adj }}=0.045\right)$. All details are summarized in Table S4 (Supporting Information). We identified tryptic peptide fragments from the VP3 part of the polyprotein. ${ }^{41} \mathrm{We}$ detected DWV protein in brains of sterile workers originating from two out of three investigated colonies; in the third colony no DWV was detected at all (Figure 5). When omitting the three replicates from the colony in which no viral proteins were detected, the nine replicates of the two infected colonies, revealed an 18-fold increase of virus protein in sterile workers $\left(p_{\text {adj }}<0.001\right)$, which reflects an on/off situation as no signal 


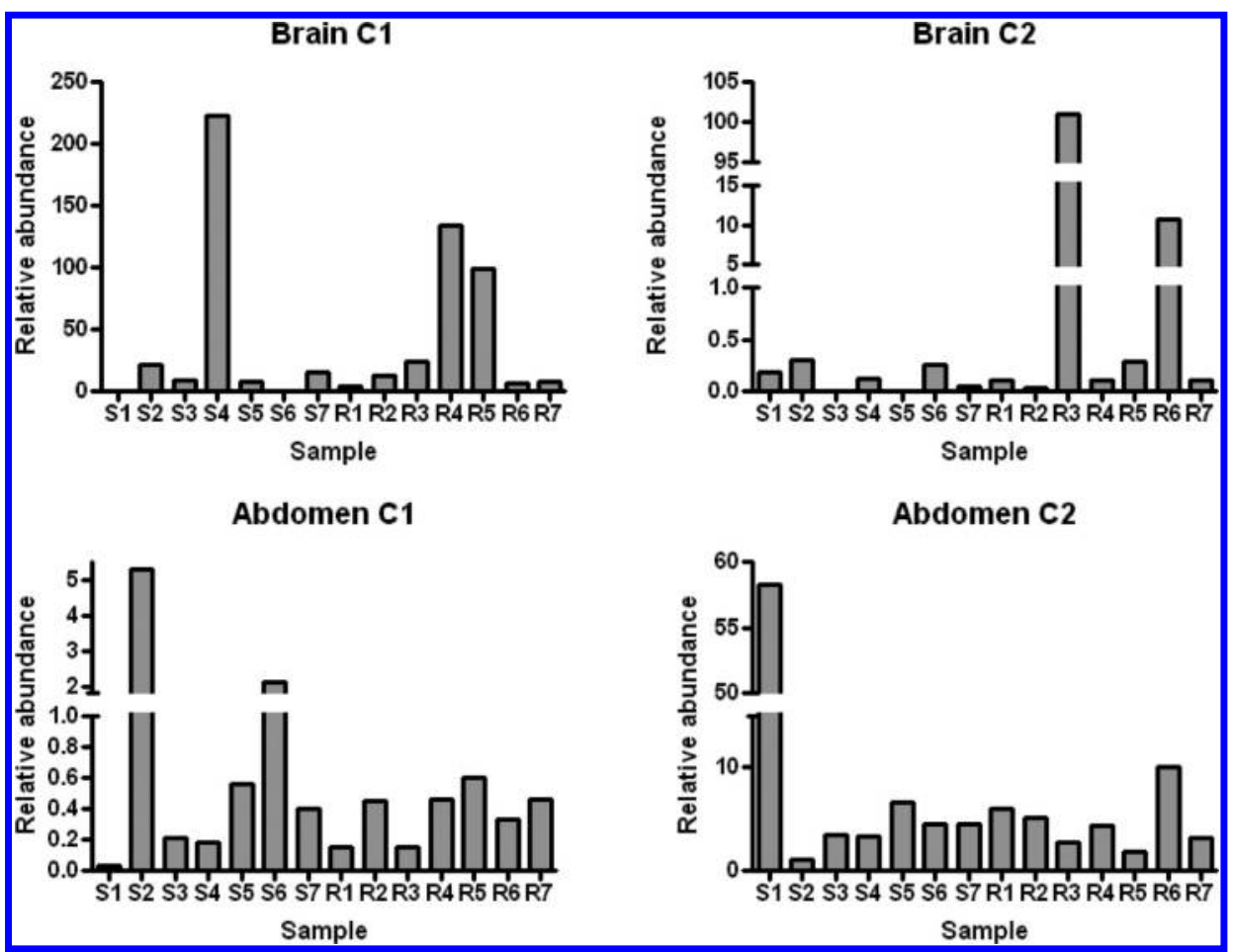

Figure 3. Overview of all relative abundances of DWV transcript in brain and abdomen. Samples originate from sterile (S) and reproductive (R) bees, collected from two colonies ( $\mathrm{C} 1$ and $\mathrm{C} 2)$. Relative abundance is displayed for each sample.

above the background was detected in reproductive workers (Figure 5).

\section{Functional Enrichment Analysis}

The enrichment analysis on the set of differential proteins upregulated in activated ovaries results in significant enrichment of $18 \mathrm{GO}$ terms (Tables 1 and S2, Supporting Information). Enriched terms deal with protein folding, response to heat and stress and subcellular transportation, endocytosis and phagocytosis. The enrichment analysis on proteins up-regulated in rudimentary ovaries results in 43 significantly enriched GO terms (Tables 1 and S3, Supporting Information) involving GO-terms dealing with the cell cycle and cell division, and metabolism of sugar, pyruvate and alcohol.

\section{RNA Analysis of Deformed Wing Virus}

We detect the DWV virus in nearly every bee (Figure 3). A small number of bees contain 10- to 100-fold more viral RNA than all other samples; however there is no correlation between the samples from reproductive and sterile bees. In particular, two abdomens in colony one and one abdomen in colony three contain remarkably high viral loads; all three were sterile bees. As for brains, five samples (one from a sterile bee, four from reproductive bees) are found to contain more virus than all 23 others. Three of these samples originate from colony one and two from colony two (Figure 3).

\section{DISCUSSION}

Despite an overall resemblance of the 2-dimensional gel images of active and rudimentary ovaries (Figure 4), there are pronounced differences which were quantitatively analyzed by means of a 2D-DIGE experiment. We expected a subset of yolk-proteins to be nearly uniquely expressed in activated ovaries and could observe that the major yolk protein, vitellogenin (Vg), is largely up-regulated (e.g., spot nrs. 293 and 298; up to 11 -fold; $p=0.0012$ ). We also expected that

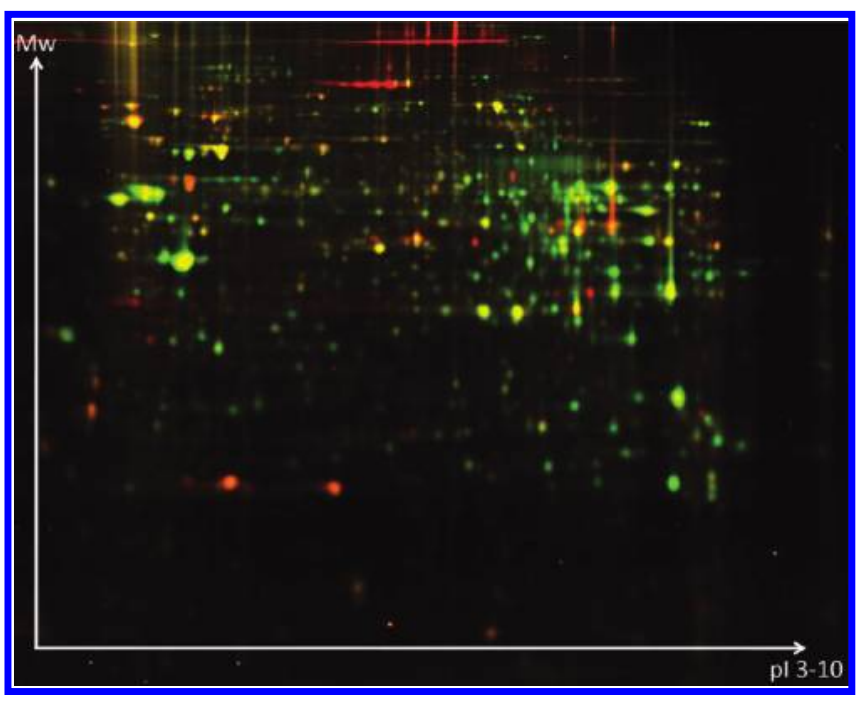

Figure 4. Representative 2D-DIGE image acquired with Ettan DIGE Imager, displaying the inactivated worker ovary proteome (green) and activated worker ovary proteome (red). Identified spots are indicated with corresponding spot number in Figure S1 (Supporting Information).

structural proteins would be relatively enriched in rudimentary ovaries and we found that tubulin and actin-87E, for instance, here contained in several differential spots, have ratios higher than 2 (e.g., spot nr. 1522, 1101; $p<0.01$ ). Remarkably, 47 of the identified proteins have previously been demonstrated to be part of the spermathecal fluid of honeybee queens. ${ }^{42}$ Spermathecae in worker bees are rudimentary, that is, they are barely visible while dissecting. Nevertheless, 31 of the 47 spermathecal proteins are differentially expressed, 15 of which are up-regulated in rudimentary ovaries and 16 are up-regulated in activated ovaries (Table S1, Supporting Information). 
Consequentially the differential expression of these proteins is probably not due to possible contamination by the rudimentary spermathecae in the ovary samples.

When we compare the present ovary proteomics data with published data obtained by microarray studies on worker ovary activation (the work of G. Thompson and C. Grozinger ${ }^{20-22}$ and our own work ${ }^{38}$ ), we found no significant overlap. However, microarray experiments studying the effect of brood pheromone ${ }^{18}$ and queen mandibular pheromone $(\mathrm{QMP})^{19}$ did reveal common differential genes depicted in Table S1 (Supporting Information). Examples are highlighted in the following paragraphs.

\section{Functional Enrichment Analysis}

The enrichment analysis (Tables 1, S2 and S3, Supporting Information) shows that proteins linked to the metabolism of several substrates (carbohydrate, alcohol, lipid, pyruvate, fatty acid, etc.) are up-regulated in rudimentary ovaries. This more than 2-fold enrichment (FE) points to an enhanced metabolism. As expected for inactive ovaries, the cell cycle and cell organization might be predicted to be inhibited, based on the enriched GO-terms in the ovaries of sterile bees (FE of nearly 3 ) that are associated with negative regulation of cell cycle, nuclear division, organelle organization etc. This conclusion, however, is based on the differential expression of only 3 identified proteins-two isomorphs of tubulin $\alpha 1$ (GB10009 and GB10514) and aldolase (GB19460) — which are also known to have various other functions and their main function is not solely the regulation of the cell cycle or nuclear division. Moreover, the up-regulation in inactivated ovaries of the proteins vibrator (GB10590; ratio $=1.6 ; p=0.016)^{43,44}$ and hu li tai shao (GB 15113; ratio $=1.5 ; p=0.02)^{45,46}$ points to an ongoing oogenic process. This finding argues against the straightforward interpretation of the repression of ovary activation as a one-way process. Suppression of ovary activation might involve a constant interplay between primordial oogenesis and subsequent degradation. ${ }^{47}$ Indeed, this may explain the enduring potency of honeybee workers to activate their ovaries. In further support of this idea is that protein degradation-related proteins, such as Cathepsin D (GB16903; ratio $=1.84 ; p=0.02)$, proteasome subunit alpha type 1 (GB11284; ratio $=1.76 ; p=0.01)$ and the proteasome $25 \mathrm{kD}$ subunit (GB10390; ratio $=1.84 ; p=0.005$ ) are also upregulated in the ovaries of sterile workers. A continuous primordial oogenesis and subsequent degradation could also account for the enrichment of metabolism-linked GO-terms described above. Although we did not identify proteins that directly point toward the suppression of ovary activation, the receptor of activated protein kinase 1 (GB11076; ratio $=2.1 ; p$ $=0.003$ ), which is up-regulated in suppressed ovaries, might be part of a key regulating network in the activation process. Protein kinases are well-known components of signaling pathways which are often activated by the binding of a ligand to a G-protein coupled receptor. Unfortunately, G-protein coupled receptors and their ligands (mostly peptides) are not detectable using a 2D-DIGE approach, ${ }^{39}$ but we did find that the $\beta$-subunit (GB15307; ratio $=3.7 ; p=0.001$ ) of one Gprotein is up-regulated in inactivated ovaries. In addition, the protein annotated as thioredoxin peroxidase (GB19380, ratio = $-3.7, p$-value $=0.002$ ) and known to inhibit apoptosis ${ }^{48}$ is upregulated in activated ovaries. Inhibition of apoptosis is mandatory to let the oocytes develop into viable, fully developed eggs.
Proteins annotated with GO-terms related to oogenesis would be expected to be enriched in activated ovaries. Yet, we could not find specifically enriched GO-terms that are associated with meiosis or egg development as such. Nevertheless, one of the significantly enriched GO-terms in activated ovaries is vesicle mediated transport (GO:0016192; FE: 2.4; Tab. 1). Through endocytosis, the developing eggs take up large amounts of maternal products, such as RNA and vitellogenin. The ATP needed for this active transport and uptake, is probably produced within the ovaries or eggs as the term 'ATP synthesis coupled proton transport' is enriched as well (GO:0015986; FE: 2.8; Table 1).

\section{Putative Key Regulating Proteins}

Twelve out of the 66 up-regulated proteins in activated ovaries are chaperones or heat shock protein-linked proteins. These heat shock-proteins cause the enrichment of the GO-terms "response to stress" (GO:0006950; FE: 3.3) and "response to heat" (GO:0009408; FE: 2.9) (Table 1). In mice, heat shock proteins (hsp) and chaperones are major constituents of oocytes. ${ }^{49}$ Moreover, it has been reported that hsp 70 and hsp 90 are present on the oolemma. ${ }^{50}$ An explanation put forward is that hsps act as chaperones in the incorporation of proteins in the zona pellucida during its formation. ${ }^{51}$ However, no evidence for this hypothesis has been presented yet. Interestingly, in vertebrates, hsp 70 and hsp 90 are also known to be part of the steroid receptor complex. ${ }^{52}$ An essential part of this complex is one or more proteins containing tetratricopeptide repeats, such as FKBP52. ${ }^{53}$ We found the Apis mellifera homologue, FKBP59 (GB13770; ratio $=-6.1 ; p=0.001)$, up-regulated in activated ovaries in this study (Table S1, Supporting Information) and it has also been detected in a microarray study showing a downregulation in worker brains upon QMP-treatment. ${ }^{19}$ In honeybees, the queen signals her presence to the worker bee population by means of pheromones, including QMP. In the presence of QMP, the worker caste remains sterile. FKBP59 is a binding protein of FK506, which is an agonist for TOR (Target of rapamycin) and necessary for the development of a larva into a queen. ${ }^{54}$ FKBP46, which is part of the ultraspiracle-ecydsone receptor complex, was not identified. ${ }^{55}$ The hsp 90 organizing protein (GB19425; ratio $=-7.4 ; p=0.001$; Table S1, Supporting Information) is known to be part of the 20hydroxyecdysone $(20 \mathrm{E})$ receptor complex ${ }^{56}$ and is more than 7 times up-regulated in activated ovaries, and the transcripts of this gene are down-regulated in worker brains upon QMPtreatment. ${ }^{19}$ In addition, spot 1090 is significantly up-regulated in activated ovaries, and contains a protein identified as "similar to Sterol carrier protein X-related thiolase CG17320-PA" (ratio $=-1.5, p$-value $=0.02$ ). One of the GO-terms of this protein is the binding of sterol. Although we did not identify a steroid receptor in this experiment, the identification of differential occurrence of heat shock proteins, proteins containing tetratricopeptide repeats and a potential carrier of steroid hormones could suggest a role for steroid signaling in oogenesis in worker bees, which so far has not been demonstrated. ${ }^{57,58}$ This suggestion is in agreement with a transcriptomic study, that reported that Ecdysone-induced gene 74 and the Broad complex are significantly up-regulated in the whole body of reproductive worker bees, when compared to sterile bees. ${ }^{38}$ These results shed a new light on the role of ecdysteroids on honeybee worker reproduction, which has been contested in the past. ${ }^{57-59}$ 


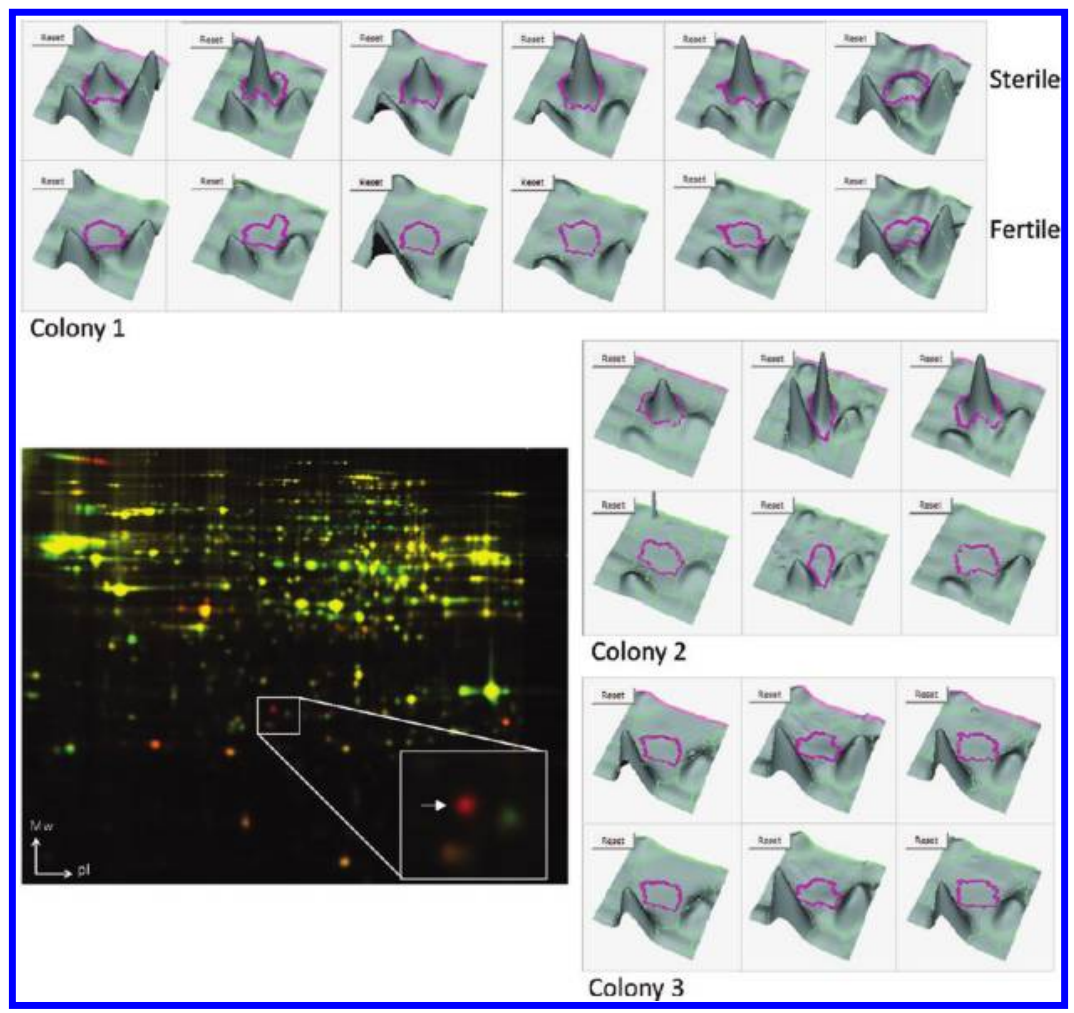

Figure 5. Representative 2D-DIGE image of the brain proteome, displaying samples of sterile worker bees in red and reproductive worker bees in green. The 3D-images clearly demonstrate the presence of the DWV protein in the sterile bees of colonies 1 and 2 (upper graphs in each series) and the nondetection in the reproductive bees (lower graphs in each series). No viral proteins were detected in colony 3 at all (3D-images are exported from the Decyder 7.0 software, GE Healthcare).

GB19373, annotated as Dipeptidyl aminopeptidase III, is upregulated in activated ovaries (ratio $=-1.7 ; p=0.017$ ). This peptidase has been found to be both a cytosolic and membranebound hydrolase which targets, among others, proctolin at the Tyr-Leu bond. ${ }^{60}$ Proctolin is a small neuropeptide, well-known in insects for its myotropic function ${ }^{61}$ and stimulatory effect on oviduct contraction. ${ }^{62}$ Although the peptide ${ }^{63}$ and its receptor, ${ }^{64}$ have not yet been demonstrated in Apis mellifera, it has been reported that queens start laying significantly more eggs and multiple eggs per cell upon proctolin injection. ${ }^{65}$ However, the activity of Dipeptidyl aminopeptidase III might not be limited to the cleavage of proctolin alone. The presence of allatostatin ${ }^{66,67}$ and its receptor, ${ }^{68}$ pheromone biosynthesis activating neuropeptides, ${ }^{69}$ adipokinetic hormone $(\mathrm{AKH})^{70}$ and insulin-like peptides ${ }^{71}$ have been reported in insect ovaries. These peptides have honeybee orthologues and their sequences contain the Tyr-Leu, or the similar Tyr-Ile, cleavage-site; except for AKH. The presence of a protein convertase in activated ovaries might suggest that neuropeptides are regulators of ovary activation, as has been shown for allatostatin. ${ }^{72,73}$ Furthermore, allatostatin has been found to be up-regulated in sterile workers in a microarray comparing whole body RNA-profiles of sterile and reproductive workers. ${ }^{38}$ We assume that the absence of a queen and brood are detected in the antennae and processed in the brain. This information is then transferred toward the ovaries through the hemolymph and might be mediated by (neuro)hormones, such as neuropeptides and steroid hormones.

\section{Differential Viral Loads}

Surprisingly, one of the spots with the highest up-regulation in rudimentary ovaries (ratio $=3.8 ; p=0.006$ ) is the polyprotein of the Kakugo-virus (KV). Also, one of the two significantly differential spots in the brain experiment is the polyprotein of DWV (9-fold up-regulated in sterile workers, $p=0.045$ ). Both $\mathrm{KV}$ and $\mathrm{DWV}$ are picorna-like viruses and $\mathrm{KV}$ is potentially linked to aggressive behavior in honeybees, ${ }^{74,75}$ whereas DWV is linked with wing deformations. ${ }^{76}$ Due to the strong homology between those honeybee viruses, we are not able to discern whether the virus identified in our study is the Kakugo virus, Deformed wing virus or a third virus, the Varroa destructor virus. However, as more and more recombinants of those viruses are being identified (e.g., see refs 77-79), it becomes likely that they are variants of the same virus. Particularly interesting is that no viral proteins could be detected in the brains of both sterile and reproductive bees of the third colony (Figure 5).

Our proteomic data suggest that activated ovaries, including mature eggs, contain lower viral protein concentrations. DWV proteins are not even detected in brains of reproductive workers. However, it is highly intriguing that the findings of several proteomic experiments on several colonies and sample collections in different years are not validated at the RNA-level. Taken together, we found more viral proteins in the brain (9 replicates from 2 colonies), ovaries (4 replicates from 2 colonies) and the hemolymph ( 5 replicates from 2 colonies ${ }^{25}$ ) of sterile workers. This finding is in agreement with a wholebody transcriptome analysis of 16 biological replicates, which reports that the GO term "viral assembly, maturation, egress and release" is significantly enriched in the sterile worker bees. $^{38}$

Additional evidence for the higher viral load in worker ovaries is the up-regulation of the aforementioned thioredoxin peroxidase 1 which is also linked to insect immune defense 
against viruses. ${ }^{25,80}$ The fact that this potential immune system component is more abundant in the activated ovaries, might indicate that fertile workers are better able to control the RNAvirus, resulting in lower viral concentrations. The ovaries of infected queens, on the other hand, show signs of degeneration, although no decreased fertility was observed. ${ }^{81}$

From the qRT-PCR data, we can conclude that almost every bee is infected with DWV, and approximately equal percentages of reproductive and sterile bees show highly elevated virus titers. One could speculate that the viral protein detected in the proteomics experiments is due to a pooling effect in which only a small number of severely infected bees in a pool cause the differential viral load. This is, however, very unlikely based on the finding that highly infected bees include sterile as well as reproductive bees. Consequently, one would expect that the chance of sampling a severely infected bee in a pool is equal (50\%) for both sterile and reproductive bees. For the brain experiment, this implies that the chance that our finding is caused by such a coincidence is less than $0.2 \%\left(0.5^{9}\right)$ when we take only the two colonies (nine replicates) into account in which we detected the virus (Figure 5).

DWV and other highly similar viruses have already been reported in honeybee brains. ${ }^{82,83}$ It has been shown that infected bees have learning deficits in certain settings. ${ }^{84}$ In another study comparing sterile and reproductive bees in a queenless colony, it has been suggested, based on transcriptional data, that sterile workers may start to forage earlier than reproductive bees. ${ }^{38}$ One might wonder whether this early onset of foraging is induced by the virus. Theory predicts that worker bees will remove themselves from the colony, by performing riskier tasks, in order to protect the rest of the colony. ${ }^{85,86}$ It is tempting to speculate that the early foraging and learning deficits of the infected bees might increase the fitness of the virus itself. When an infected bee gets lost and manages to intrude into another colony, the virus may be transmitted to another colony. It is conceivable that the virus actively steers honeybee behavior, given that it has been found in the brain. ${ }^{82}$

Several reasons can be put forward to explain the difference between the outcomes of our qRT-PCR and proteome experiments. First, our RNA and protein extracts, unfortunately, were not obtained from the same individuals, which could have delivered additional insight in this matter. The present qRT-PCR experiments have been carried out with bees obtained from another apiary in a different year and on worker bees which are the offspring of naturally mated queens, instead of singly mated (instrumentally inseminated) queens that were used in the proteomics experiment. However, the impact of those factors is likely minimal, as a similar approach has already proven to be successful. ${ }^{38}$ Second, the qRT-PCR validation for the ovaries were performed on complete abdomens, instead of dissected ovaries. Third, the experimental colonies did not contain an unusual high number of parasitic mites or bees with deformed wings and no bees with deformed wings were included in the analysis. We are dealing with covert infections in both sterile and reproductive bees. Yet, it might be possible that the infections in reproductive bees are rather persistent, lacking viral replication, while in the sterile workers, the virus is actively replicating (for nomenclature $\operatorname{se}^{76}$ ). The active replication of the virus requires that the RNA genome of DWV is accessible for translation and that the proteins have not (yet) formed a solid capsid protecting the viral genome. Continuing on this line of reasoning, it might be possible that our lysis solution for proteomics is not able to separate the viral proteins from a solid virus particle and only solubilizes free viral proteins, whereas the phenol-based RNA extraction does successfully break down the viral capsids and releases the viral RNA. The virus particles are known to be resistant to numerous factors, as even isolated virus particles keep their virulence. ${ }^{87}$ By consequence, via proteomics, we could actually be assessing viral replication while we determine complete viral loads using GRT-PCR. This is however, highly speculative and is definitely worth investigating in the future.

\section{CONCLUSIONS}

This work presents a 2DE spot map of both activated and inactivated honeybee worker ovaries. The data serve as a solid base for future research on reproductive regulation in social insects. The quantitative information provides insights in reproductive physiology, with homologies in vertebrates. Our experimental setup in a queenless colony provides a unique opportunity for research on the regulation of reproduction by comparing sterile and reproducing sisters of the same age, which is nearly impossible for most vertebrate model organisms. The observation of the DWV infection opens new avenues for the study of DWV reproduction and honeybee immunity.

\section{ASSOCIATED CONTENT}

\section{Supporting Information}

Supplemental tables and figure. This material is available free of charge via the Internet at http://pubs.acs.org.

\section{AUTHOR INFORMATION}

\section{Corresponding Author}

*Naamsestraat 59 B-3000, Leuven, Belgium, dries.cardoen@ bio.kuleuven.be, Tel +32 163239 44, fax +32 16323902 .

Notes

The authors declare no competing financial interest.

\section{ACKNOWLEDGMENTS}

We gratefully acknowledge the Research Foundation of Flanders (FWO-Flanders G041708N, G062811N and KAN 1.5.199.10N, 1.5.091.08) and the K.U.Leuven Research Foundation (GOA 2010/14) for financial support. D.C. and U.E. are funded by the Institute for the Promotion of Innovation through Science and Technology in Flanders (IWT-Vlaanderen). B.B. is an FWO fellow and P.V. is an FWO postdoc. MALDI-TOF (Ultraflex) analysis has been carried out at ProMeta, K.U.Leuven. Thanks to I. Timmermans for ovary pictures, K. Vandingenen for 2D-DIGE assistance, HP Vandersmissen for support with RNA samples, Prof. Dr. J. Vanden Broeck for the qRT-PCR device, Prof. E. Blumenthal for revising the language and F. Kowlier for support.

\section{ABBREVIATIONS}

2-DE, 2-dimensional electrophoresis; 2D-DIGE, 2-dimensional differential gel electrophoresis; CHAPS, 3-[(3-cholamidopropyl)-dimethylammonio]-propane-sulfonate; DTT, dithiothreitol; DWV, deformed wing virus; FDR, false discovery rate; FE, fold enrichment; GO, gene ontology; Hsp, heat shock protein; KV, Kakugo virus; PMF, peptide mass fingerprinting; qRT-PCR, quantative real-time polymerase chain reaction; $R G P H$, reproductive ground plan hypothesis; VP, Viral protein 


\section{REFERENCES}

(1) Ratnieks, F. L. W.; Foster, K. R; Wenseleers, T. Darwin's special difficulty: the evolution of "neuter insects" and current theory. Behav. Ecol. Sociobiol. 2011, 65 (3), 481-492.

(2) Ratnieks, F. L.; Wenseleers, T. Altruism in insect societies and beyond: voluntary or enforced? Trends Ecol. Evol. 2008, 23 (1), 45-52.

(3) Snodgrass, R. E. Anatomy of the honey bee; Comstock Pub. Associates: Ithaca, NY, 1984; pp 1-334.

(4) Capella, I. C. S.; Hartfelder, K. Juvenile hormone effect on DNA synthesis and apoptosis in caste-specific differentiation of the larval honey bee (Apis mellifera L.) ovary. J. Insect Physiol. 1998, 44 (5-6), 385-391.

(5) Miller, D. G.; Ratnieks, F. L. W. The timing of worker reproduction and breakdown of policing behaviour in queenless honey bee (Apis mellifera L.) societies. Insect. Soc 2001, 48 (2), 178-184.

(6) West-Eberhard, M. J. Phenotypic Plasticity and the Origins of Diversity. Annu. Rev. Ecol. S 1989, 20, 249-278.

(7) West-Eberhard, M. J. Wasp societies as microcosms for the study of development and evolution. In In Natural history and evloution of paperwasps; Turillazzi, S., West-Eberhard, M. J., Eds.; Oxford University Press: New York, 1996; pp 290-317.

(8) Amdam, G. V.; Norberg, K.; Fondrk, M. K.; Page, R. E., Jr. Reproductive ground plan may mediate colony-level selection effects on individual foraging behavior in honey bees. Proc. Natl. Acad. Sci. U.S.A. 2004, 101 (31), 11350-11355.

(9) Bloch, G.; Grozinger, C. M. Social molecular pathways and the evolution of bee societies. Phil. Trans. R. Soc. B 2011, 366 (1574), 2155-2170.

(10) Toth, A. L.; Robinson, G. E. Evo-devo and the evolution of social behavior. Trends Genet. 2007, 23 (7), 334-341.

(11) Oldroyd, B. P.; Beekman, M. Effects of selection for honey bee worker reproduction on foraging traits. PLoS Biol. 2008, 6 (3), e56.

(12) Pennisi, E. Behavioral ecology. Sex and social structure. Science 2009, 326 (5952), 518-519.

(13) Amdam, G. V.; Page, R. E. The developmental genetics and physiology of honeybee societies. Anim. Behav. 2010, 79 (5), 973-980.

(14) Makert, G. R.; Paxton, R. J.; Hartfelder, K. Ovariole number - a predictor of differential reproductive success among worker subfamilies in queenless honeybee (Apis mellifera L.) colonies. Behav. Ecol. Sociobiol. 2006, 60 (6), 815-825.

(15) The Honeybee Genome Sequencing Consortium.. Insights into social insects from the genome of the honeybee Apis mellifera. Nature 2006, 443 (7114), 931-949.

(16) Alaux, C.; Robinson, G. E. Alarm pheromone induces immediate-early gene expression and slow behavioral response in honey bees. J. Chem. Ecol. 2007, 33 (7), 1346-1350.

(17) Alaux, C.; Sinha, S.; Hasadsri, L.; Hunt, G. J.; Guzman-Novoa, E.; Grandi-Hoffman, G.; Uribe-Rubio, J. L.; Southey, B. R.; RodriguezZas, S.; Robinson, G. E. Honey bee aggression supports a link between gene regulation and behavioral evolution. Proc. Natl. Acad. Sci. U.S.A. 2009, 106 (36), 15400-15405.

(18) Alaux, C.; Le Conte, Y.; Adams, H. A.; Rodriguez-Zas, S.; Grozinger, C. M.; Sinha, S.; Robinson, G. E. Regulation of brain gene expression in honey bees by brood pheromone. Genes Brain Behav. 2009, 8 (3), 309-319.

(19) Grozinger, C. M.; Sharabash, N. M.; Whitfield, C. W.; Robinson, G. E. Pheromone-mediated gene expression in the honey bee brain. Proc. Natl. Acad. Sci. U.S.A. 2003, 100 (Suppl 2), 14519-14525.

(20) Grozinger, C. M.; Fan, Y.; Hoover, S. E.; Winston, M. L. Genome-wide analysis reveals differences in brain gene expression patterns associated with caste and reproductive status in honey bees (Apis mellifera). Mol. Ecol. 2007, 16 (22), 4837-4848.

(21) Thompson, G. J.; Kucharski, R; Maleszka, R.; Oldroyd, B. P. Towards a molecular definition of worker sterility: differential gene expression and reproductive plasticity in honey bees. Insect Mol. Biol. 2006, 15 (5), 637-644.

(22) Thompson, G. J.; Kucharski, R.; Maleszka, R.; Oldroyd, B. P. Genome-wide analysis of genes related to ovary activation in worker honey bees. Insect Mol. Biol. 2008, 17 (6), 657-665.
(23) Chan, Q. W.; Howes, C. G.; Foster, L. J. Quantitative comparison of caste differences in honeybee hemolymph. Mol. Cell Proteomics 2006, 5 (12), 2252-2262.

(24) Wolschin, F.; Amdam, G. V. Comparative proteomics reveal characteristics of life-history transitions in a social insect. Proteome Sci. 2007, 5, 10.

(25) Cardoen, D.; Ernst, U. R.; Van Vaerenbergh, M.; Boerjan, B.; de Graaf, D. C.; Wenseleers, T.; Schoofs, L.; Verleyen, P. Differential Proteomics in Dequeened Honeybee Colonies Reveals Lower Viral Load in Hemolymph of Fertile Worker Bees. PLoS ONE 2011, 6 (6), e20043.

(26) Seeley, T. D. The Wisdom of the Hive; Harvard University Press: London, 1995.

(27) Bradford, M. M. Rapid and Sensitive Method for Quantitation of Microgram Quantities of Protein Utilizing Principle of Protein-Dye Binding. Anal. Biochem. 1976, 72 (1-2), 248-254.

(28) Bogaerts, A.; Baggerman, G.; Vierstraete, E.; Schoofs, L.; Verleyen, P. The hemolymph proteome of the honeybee: gel-based or gel-free? Proteomics 2009, 9 (11), 3201-3208.

(29) Smyth, G. Limma: linear models for microarray data. Bioinformatics and computational biology solutions using $R$ and Bioconductor; Springer: New York, 2005; pp 397-420.

(30) Fodor, I. K.; Nelson, D. O.; Alegria-Hartman, M.; Robbins, K.; Langlois, R. G.; Turteltaub, K. W.; Corzett, T. H.; Cutchen-Maloney, S. L. Statistical challenges in the analysis of two-dimensional difference gel electrophoresis experiments using DeCyderTM. Bioinformatics 2005, 21 (19), 3733-3740.

(31) Kultima, K.; Scholz, B.; Alm, H.; Skold, K.; Svensson, M.; Crossman, A.; Bezard, E.; Andren, P.; Lonnstedt, I. Normalization and expression changes in predefined sets of proteins using 2D gel electrophoresis: A proteomic study of L-DOPA induced dyskinesia in an animal model of Parkinson's disease using DIGE. BMC Bioinform. 2006, 7 (1), 475.

(32) Mittal, A.; Phillips, A. R; Middleditch, M.; Ruggiero, K.; Loveday, B.; Delahunt, B.; Cooper, G. J.; Windsor, J. A. The proteome of mesenteric lymph during acute pancreatitis and implications for treatment. J. Pancreas 2009, 10 (2), 130-142.

(33) Scholz, B.; Svensson, M.; Alm, H.; Skold, K.; Falth, M.; Kultima, K.; Guigoni, C.; Doudnikoff, E.; Li, Q.; Crossman, A. R; Bezard, E.; Andren, P. E. Striatal proteomic analysis suggests that first L-dopa dose equates to chronic exposure. PLoS. ONE 2008, 3 (2), e1589.

(34) Benjamini, Y.; Hochberg, Y. Controlling the false discovery rate - a practical and powerful approach to multiple testing. J. R. Stat. Soc. B 1995, 57 (1), 289-300.

(35) Vierstraete, E.; Cerstiaens, A.; Baggerman, G.; Van den Bergh, G.; De Loof, A.; Schoofs, L. Proteomics in Drosophila melanogaster: first 2D database of larval hemolymph proteins. Biochem. Biophys. Res. Commun. 2003, 304 (4), 831-838.

(36) Perkins, D. N.; Pappin, D. J. C.; Creasy, D. M.; Cottrell, J. S. Probability-based protein identification by searching sequence databases using mass spectrometry data. Electrophoresis 1999, 20 (18), $3551-3567$

(37) Alexa, A.; Rahnenfuhrer, J.; Lengauer, T. Improved scoring of functional groups from gene expression data by decorrelating GO graph structure. Bioinformatics 2006, 22 (13), 1600-1607.

(38) Cardoen, D.; Wenseleers, T.; Ernst, U. R.; Danneels, E. L.; Laget, D.; De, G.; Schoofs, L.; Verleyen, P. Genome-wide analysis of alternative reproductive phenotypes in honeybee workers. Mol. Ecol. 2011, 20 (19), 4070-4084.

(39) Martyniuk, C. J.; Denslow, N. D. Towards functional genomics in fish using quantitative proteomics. Gen. Comp. Endrocrinol. 2011, $164(2-3), 135-141$.

(40) Livak, K. J.; Schmittgen, T. D. Analysis of Relative Gene Expression Data Using Real-Time Quantitative PCR and the 2-[delta] [delta] CT Method. Methods 2001, 25 (4), 402-408.

(41) Lanzi, G.; De Miranda, J. R.; Boniotti, M. B.; Cameron, C. E.; Lavazza, A.; Capucci, L.; Camazine, S. M.; Rossi, C. Molecular and biological characterization of deformed wing virus of honeybees (Apis mellifera L.). J. Virol. 2006, 80 (10), 4998-5009. 
(42) Baer, B.; Eubel, H.; Taylor, N. L.; O’Toole, N.; Millar, A. H. Insights into female sperm storage from the spermathecal fluid proteome of the honeybee Apis mellifera. Genome Biol. 2009, 10 (6), R67.

(43) Gatt, M. K.; Glover, D. M. The Drosophila phosphatidylinositol transfer protein encoded by vibrator is essential to maintain cleavagefurrow ingression in cytokinesis. J. Cell Sci. 2006, 119 (Pt 11), 22252235.

(44) Giansanti, M. G.; Bonaccorsi, S.; Kurek, R.; Farkas, R. M.; Dimitri, P.; Fuller, M. T.; Gatti, M. The Class I PITP Giotto Is Required for Drosophila Cytokinesis. Curr. Biol. 2006, 16 (2), 195201.

(45) Yue, L.; Spradling, A. C. hu-li tai shao, a gene required for ring canal formation during Drosophila oogenesis, encodes a homolog of adducin. Gene. Dev. 1992, 6 (12b), 2443-2454.

(46) Wilson, P. G. Centrosome inheritance in the male germ line of Drosophila requires hu-li tai-shao function. Cell Biol. Int. 2005, 29 (5), 360-369.

(47) Tanaka, E. D.; Hartfelder, K. The initial stages of oogenesis and their relation to differential fertility in the honey bee (Apis mellifera) castes. Arthropod. Struct. Dev. 2004, 33 (4), 431-442.

(48) Zhang, P.; Liu, B.; Kang, S. W.; Seo, M. S.; Rhee, S. G.; Obeid, L. M. Thioredoxin Peroxidase Is a Novel Inhibitor of Apoptosis with a Mechanism Distinct from That of Bcl-2. J. Biol. Chem. 1997, 272 (49), 30615-30618.

(49) Yurttas, P.; Morency, E.; Coonrod, S. A. Use of proteomics to identify highly abundant maternal factors that drive the egg-to-embryo transition. Reproduction 2010, 139 (5), 809-823.

(50) Calvert, M. E.; Digilio, L. C.; Herr, J. C.; Coonrod, S. A. Oolemmal proteomics--identification of highly abundant heat shock proteins and molecular chaperones in the mature mouse egg and their localization on the plasma membrane. Reprod. Biol. Endocrinol. 2003, 1, 27.

(51) Liang, L. F.; Chamow, S. M.; Dean, J. Oocyte-Specific Expression of Mouse Zp-2 - Developmental Regulation of the ZonaPellucida Genes. Mol. Cell. Biol. 1990, 10 (4), 1507-1515.

(52) Pratt, W. B.; Toft, D. O. Steroid receptor interactions with heat shock protein and immunophilin chaperones. Endocr. Rev. 1997, 18 (3), 306-360.

(53) Silverstein, A. M.; Galigniana, M. D.; Kanelakis, K. C.; Radanyi, C.; Renoir, J. M.; Pratt, W. B. Different regions of the immunophilin FKBP52 determine its association with the glucocorticoid receptor, hsp90, and cytoplasmic dynein. J. Biol. Chem. 1999, 274 (52), 3698036986.

(54) Patel, A.; Fondrk, M. K.; Kaftanoglu, O.; Emore, C.; Hunt, G.; Frederick, K.; Amdam, G. V. The Making of a Queen: TOR Pathway Is a Key Player in Diphenic Caste Development. PLoS ONE 2007, 2 (6), e509.

(55) Song, Q.; Alnemri, E. S.; Litwack, G.; Gilbert, L. I. An Immunophilin is a component of the insect ecdysone receptor $(\mathrm{EcR})$ Complex. Insect Biochem. Mol. Biol. 1998, 27 (11), 973-982.

(56) Gilbert, L. I.; Granger, A.; Roe, R. M. The juvenile hormones: historical facts and speculations on future research directions. Insect Biochem. Mol. Biol. 2000, 30 (8-9), 617-644.

(57) Hartfelder, K.; Bitondi, M. M. G.; Santana, W. C.; Simoes, Z. L. P. Ecdysteroid titer and reproduction in queens and workers of the honey bee and of a stingless bee: loss of ecdysteroid function at increasing levels of sociality? Insect Biochem. Mol. Biol. 2002, 32 (2), 211-216.

(58) Robinson, G. E.; Vargo, E. L. Juvenile hormone in adult eusocial Hymenoptera: gonadotropin and behavioral pacemaker. Arch. Insect Biochem. Physiol. 1997, 35 (4), 559-583.

(59) Robinson, G. E.; Strambi, C.; Strambi, A.; Feldlaufer, M. F. Comparison of Juvenile-Hormone and Ecdysteroid Hemolymph Titers in Adult Worker and Queen Honey-Bees (Apis-Mellifera). J. Insect Physiol. 1991, 37 (12), 929-935.

(60) Mazzocco, C.; Fukasawa, K. M.; Auguste, P.; Puiroux, J. Characterization of a functionally expressed dipeptidyl aminopeptidase
III from Drosophila melanogaster. Eur. J. Biochem. 2003, 270 (14), 3074-3082.

(61) Konopinska, D.; Rosinski, G. Proctolin, an insect neuropeptide. J. Peptide Sci. 1999, 5 (12), 533-546.

(62) Spittaels, K.; Vankeerberghen, A.; Torrekens, S.; Devreese, B.; Grauwels, L.; Van Leuven, F.; Hunt, D.; Shabanowitz, J.; Schoofs, L.; Van Beeumen, J.; De Loof, A. Isolation of Ala1-proctolin, the first natural analogue of proctolin, from the brain of the Colorado potato beetle. Mol. Cell. Endocrinol. 1995, 110 (1-2), 119-124.

(63) Hummon, A. B.; Richmond, T. A.; Verleyen, P.; Baggerman, G.; Huybrechts, J.; Ewing, M. A.; Vierstraete, E.; Rodriguez-Zas, S. L.; Schoofs, L.; Robinson, G. E.; Sweedler, J. V. From the genome to the proteome: uncovering peptides in the Apis brain. Science 2006, 314 (5799), 647-649.

(64) Hauser, F.; Cazzamali, G.; Williamson, M.; Blenau, W.; Grimmelikhuijzen, C. J. P. A review of neurohormone GPCRs present in the fruitfly Drosophila melanogaster and the honey bee Apis mellifera. Prog. Neurobiol. 2006, 80 (1), 1-19.

(65) Miranda, C. R. E.; Bitondi, M. M. G.; Simoes, Z. L. P. Effect of proctolin on the egg-laying activity of Apis mellifera queens. J. Apic. Res. 2003, 42 (3), 35-38.

(66) Garside, C. S.; Koladich, P. M.; Bendena, W. G.; Tobe, S. S. Expression of allatostatin in the oviducts of the cockroach Diploptera punctata. Insect Biochem. Mol. Biol. 2002, 32 (9), 1089-1099.

(67) Woodhead, A. P.; Thompson, M. E.; Chan, K. K.; Stay, B. Allatostatin in ovaries, oviducts, and young embryos in the cockroach Diploptera punctata. J. Insect Physiol. 2003, 49 (12), 1103-1114.

(68) Gäde, G.; Marco, H. G.; Richter, D.; Weaver, R. J. Structureactivity studies with endogenous allatostatins from Periplaneta americana: Expressed receptor compared with functional bioassay. J. Insect Physiol. 2008, 54 (6), 988-996.

(69) Cheng, Y.; Luo, L.; Jiang, X.; Zhang, L.; Niu, C. Expression of pheromone biosynthesis activating neuropeptide and its receptor (PBANR) mRNA in adult female Spodoptera exigua (Lepidoptera: Noctuidae). Arch. Insect Biochem. Physiol. 2010, 75 (1), 13-27.

(70) Abdel-latief, M.; Hoffmann, K. H. The adipokinetic hormones in the fall armyworm, Spodoptera frugiperda: cDNA cloning, quantitative real time RT-PCR analysis, and gene specific localization. Insect Biochem. Mol. Biol. 2007, 37 (10), 999-1014.

(71) Maniere, G.; Rondot, I.; Bullesbach, E. E.; Gautron, F.; Vanhems, E.; Delbecque, J. P. Control of ovarian steroidogenesis by insulin-like peptides in the blowfly (Phormia regina). J. Endocrinol. 2004, 181 (1), 147-156.

(72) Wasielewski, O.; Skonieczna, M.; Kodrík, D. Role of allatostatinlike factors from the brain of Tenebrio molitor females. Arch. Insect Biochem. Physiol. 2009, 71 (4), 223-235.

(73) Garside, C. S.; Nachman, R. J.; Tobe, S. S. Injection of Dipallatostatin or Dip-allatostatin pseudopeptides into mated female Diploptera punctata inhibits endogenous rates of $\mathrm{JH}$ biosynthesis and basal oocyte growth. Insect Biochem. Mol. Biol. 2000, 30 (8-9), 703710.

(74) Fujiyuki, T.; Takeuchi, H.; Ono, M.; Ohka, S.; Sasaki, T.; Nomoto, A.; Kubo, T. Novel insect picorna-like virus identified in the brains of aggressive worker honeybees. J. Virol. 2004, 78 (3), 10931100.

(75) Rortais, A.; Tentcheva, D.; Papachristoforou, A.; Gauthier, L.; Arnold, G.; Colin, M. E.; Bergoin, M. Deformed wing virus is not related to honey bees' aggressiveness. Virol. J. 2006, 3, 61 .

(76) De Miranda, J. R.; Genersch, E. Deformed wing virus. J. Invert. Pathol. 2010, 103, S48-S61.

(77) Moore, J.; Jironkin, A.; Chandler, D.; Burroughs, N.; Evans, D. J.; Ryabov, E. V. Recombinants between Deformed wing virus and Varroa destructor virus-1 may prevail in Varroa destructor-infested honeybee colonies. J. Gen. Virol. 2011, 92 (1), 156-161.

(78) Berenyi, O.; Bakonyi, T.; Derakhshifar, I.; Koglberger, H.; Topolska, G.; Ritter, W.; Pechhacker, H.; Nowotny, N. Phylogenetic analysis of deformed wing virus genotypes from diverse geographic origins indicates recent global distribution of the virus. Appl. Environ. Microbiol. 2007, 73 (11), 3605-3611. 
(79) Terio, V.; Martella, V.; Camero, M.; Decaro, N.; Testini, G.; Bonerba, E.; Tantillo, G.; Buonavoglia, C. Detection of a honeybee iflavirus with intermediate characteristics between kakugo virus and deformed wing virus. New Microbiol. 2008, 31 (4), 439-444.

(80) Lee, K. S.; Ryul Kim, S.; Sook Park, N.; Kim, I.; Dong Kang, P.; Hee Sohn, B.; Ho Choi, K.; Woo Kang, S.; Ho, Je, Y.; Mong Lee, S.; Dae Sohn, H.; Jin, B. R. Characterization of a silkworm thioredoxin peroxidase that is induced by external temperature stimulus and viral infection. Insect Biochem. Mol. Biol. 2005, 35 (1), 73-84.

(81) Gauthier, L.; Ravallec, M.; Tournaire, M.; Cousserans, F.; Bergoin, M.; Dainat, B.; de Miranda, J. R. Viruses Associated with Ovarian Degeneration in Apis mellifera L. Queens. PLoS ONE 2011, 6 (1), e16217.

(82) Fujiyuki, T.; Matsuzaka, E.; Nakaoka, T.; Takeuchi, H.; Wakamoto, A.; Ohka, S.; Sekimizu, K.; Nomoto, A.; Kubo, T. Distribution of Kakugo Virus and Its Effects on the Gene Expression Profile in the Brain of the Worker Honeybee Apis mellifera L. J. Virol. 2009, 83 (22), 11560-11568.

(83) Shah, K.; Evans, E.; Pizzorno, M. Localization of deformed wing virus (DWV) in the brains of the honeybee, Apis mellifera Linnaeus. Virol. J. 2009, 6 (1), 182

(84) Iqbal, J.; Mueller, U. Virus infection causes specific learning deficits in honeybee foragers. Proc. R. Soc. B: Biol. Sci. 2007, 274 (1617), 1517-1521.

(85) Rueppell, O.; Hayworth, M. K.; Ross, N. P. Altruistic selfremoval of health-compromised honey bee workers from their hive. $J$. Evol. Biol. 2010, 23 (7), 1538-1546.

(86) Tofilski, A. Shorter-lived workers start foraging earlier. Insect Soc. 2009, 56 (4), 359-366.

(87) Singh, R.; Levitt, A. L.; Rajotte, E. G.; Holmes, E. C.; Ostiguy, N.; Vanengelsdorp, D.; Lipkin, W. I.; Depamphilis, C. W.; Toth, A. L.; Cox-Foster, D. L. RNA viruses in hymenopteran pollinators: evidence of inter-Taxa virus transmission via pollen and potential impact on non-Apis hymenopteran species. PLoS ONE 2010, 5 (12), e14357. 